\title{
MOTIVATORS AND BARRIERS ON SOCIAL MEDIA USAGE IN B2B FIRMS: AN APPLICATION FOR FOOD INDUSTRY
}

DOI: 10.17261/Pressacademia.2018.909

PAP- V.7-2018(62)-p.330-334

Ipek Kazancoglu' ${ }^{1}$, Enes Inan ${ }^{2}$, Hande Bilgehan ${ }^{3}$

${ }^{1}$ Ege University, Faculty of Economics And Administrative Sciences, Izmir, Turkey. ipek.savasci@ege.edu.tr, ORCID: 0000-0001-8251-5451

${ }^{2}$ Ege University, Faculty of Economics And Administrative Sciences, Izmir, Turkey. enes.inan@gmail.com, ORCID: 0000-0001-5915-0044

${ }^{3}$ Ege University, Faculty of Economics And Administrative Sciences, Izmir, Turkey.

handebilgehan@gmail.com, ORCID: 0000-0003-0844-8451

To cite this document

Kazancoglu, I., Inan, E., Bilgehan, H. (2018). Motivators and barriers on social media usage in B2B firms: an application for food industry. PressAcademia Procedia (PAP), V.7, p.330-334.

Permemant link to this document: http://doi.org/10.17261/Pressacademia.2018.909

Copyright: Published by PressAcademia and limited licenced re-use rights only.

\section{ABSTRACT}

Purpose- The purpose of this study is to investigate motivation factors and barriers on social media communication of B2B companies in food industry.

Methodology- Using the semi-structured interview form, one of the qualitative research methods, in-depth interviews were conducted with the managers and experts of four companies in the food sector who are active in industrial markets. In the study, purposeful sampling management was used. The results were obtained by using the descriptive analysis method. Depending on the conceptual framework, it was determined which theme the data obtained at the end of the interview would be organized under.

Findings- As a result of the interview; the key motivators for these companies to use social media platforms are "reaching a wider audience", "effectively interacting with the target audience and interacting with the target audience", "creating sales revenue" and "creating and increasing brand awareness" that have been identified.

Conclusion- It is thought that when the barriers in front of the B2B companies in the food industry are removed, these companies can take a more active role in their existing markets and reach and communicate with potential buyers outside of their current customer portfolio. At the same time, it is believed that when B2B food companies use their social media platforms effectively and efficiently, they can create a positive impact in capturing additional sales revenue outside traditional channels.

Keywords: Industrial marketing, business-to-business marketing (B2B), social media, motivation, barriers. JEL Codes: M10, M30, M31

\section{B2B FiRMALARDA SOSYAL MEDYA KULLANIMINI ETKILEYEN MOTIVASYON FAKTÖRLERi VE BARIYERLER: GIDA SEKTÖRÜNE YÖNELIK ÖRNEK BIR UYGULAMA}

\section{ÖZET}

Amaç - Endüstriyel pazarda faaliyet gösteren B2B firmalarının, sosyal medya platformlarını kullanmaya motive eden faktörleri ve de kullanmaktan alıkoyan bariyerleri, gıda sektöründe faaliyet gösteren firmalar örnekleminde ortaya çıkarmaktır.

Yöntem - Nitel araştırma yöntemlerinden biri olan yarı yapılandırılmış görüşme formu kullanılarak, gıda sektöründe yer alıp endüstriyel pazarda faaliyet gösteren dört firmanın yönetici ve uzmanlarıyla derinlemesine görüşmeler gerçekleştirilmiştir. Çalışmada, amaçlı örnekleme yönetimi kullanılmıştır. Elde edilen sonuçlar, betimsel analiz yöntemi kullanılarak elde edilmiştir. Kavramsal çerçeveye bağlı olarak görüşme sonunda elde edilen verilerin hangi temalar altında düzenleneceği belirlenmiştir. Düzenlenen bu veriler tanımlanarak doğrudan alıntılarla desteklenmiş ve yorumlanmıştır.

Bulgular- Görüşme sonucunda; "daha geniş hedef kitleye ulaşma”, "hedef kitleye etkin bir şekilde erişim ve hedef kitle ile etkileşim kurma" "satış geliri yaratma" ve "marka / kurum bilinirliği yaratma ve artırma"nın, bu firmaların sosyal medya platformlarını kullanmada temel motivasyon faktörleri olduğu belirlenmiştir. Ana bariyerler ise, "endüstriyel pazarın sosyal medya iletişimine ihtiyacı olmaması düşüncesi" ve "insan kaynağı ve finansal kaynak yetersizliği" olarak tespit edilmiştir.

Sonuç- Gıda sektöründe faaliyet gösteren B2B firmalarının önündeki bariyerler ortadan kaldırıldığında, bu firmaların mevcut pazarlarında daha aktif bir rol alabileceği ve mevcut müşteri portföylerinin dışındaki potansiyel alıcılara da daha rahat ulaşıp onlarla iletişime geçebilecekleri düşünülmektedir. Aynı zamanda B2B gıda firmalarının sosyal medya platformlarını etkin ve verimli bir şekilde kullandıklarında, geleneksel kanallar dışında ilave bir satış geliri yakalamada pozitif bir etki yaratabileceklerine inanılmaktadır.

Anahtar Kelimeler: Endüstriyel pazarlama, B2B, sosyal medya, motivasyon, bariyer.

JEL Kodları: M10, M30, M31 


\section{GiRiş}

Teknolojik gelişmeler, firmaların mevcut ve potansiyel müşterilerle etkileşim biçiminde önemli değişiklikler meydana getirmiştir. Web 2.0 teknolojilerinin ortaya çıkması ve sosyal medyanın artan popülaritesi, kullanıcıların internet üzerinde bilgilerini kolayca paylaştıkları, doğrudan ve etkileşimli bir iletişim aracı olmuştur. Sosyal medya platformlarına ilginin yüksek olmasına rağmen; B2C firmalarına oranla, B2B firmaları tarafından bu sosyal medya platformlarının benimsenmesi ve kullanılma düzeyleri daha düşük seviyede kalmaktadır. Literatürdeki çalışmalar incelendiğinde; B2B firmalarını sosyal medya platformlarını kullanmaya yönelten faktörlerin ve bu platformları kullanmaktan kaçınma nedenlerinin ve bariyerlerinin belirlemesine sınırlı sayıda çalışma (Michaelidou vd., 2011, Järvinen vd., 2012, Lacka ve Chong, 2016) olduğu tespit edilmiştir. Bu bağlamda çalışmanın amacı, Türkiye'de gıda sektöründe faaliyet gösteren B2B firmaları özelinde sosyal medya kullanımını etkileyen motivasyon faktörlerinin ve bariyerlerinin tespit edilmesidir. Çalışma sonuçlarının endüstriyel pazarda faaliyet gösteren firmalara da yol gösterici olacağı düşünülmektedir.

\section{LITERATÜR TARAMASI}

Sosyal Medya, Web 2.0'ın ideolojik ve teknolojik temelleri üzerine kurulmuş, aynı zamanda kullanıcılar tarafından içeriğin oluşturulmasına ve değiştirilmesine olanak tanıyan bir internet tabanlı uygulamalar grubudur (Kaplan ve Haenlein, 2010). Günümüzde firmalar tek yönlü iletişim aracı olan web sayfaları yerine; çift yönlü iletişim araçlarından Facebook, Instagram, Twitter vb. gibi sosyal medya platformlarını da bir iletişim aracı olarak kullanmaktadır. B2B kapsamında sosyal medyanın benimsenmesi, örneğin çevrimiçi alışverişte sıklıkla uygulanan B2C kapsamına göre daha yavaş ilerlemektedir (Siamagka vd., 2015). Son zamanlarda B2B firmaları pazarlama stratejilerine bir dizi çevrimiçi platform (Facebook, Linkedin, Twitter vb.) da kullanmaktadırlar (Brennan ve Croft, 2012). Sosyal medya firmaların pazarlama hedef ve stratejilerine katkıda bulunan; özellikle müşterilerin katıımı, müşteri ilişkileri yönetimi ve iletişimi açısından etkili bir mekanizma olmaktadır (Filo vd., 2015). Sosyal medya platformları hem çok popüler olması, hem de erişim ve kullanım kolaylığı nedeniyle iş ilişkileri geliştirme için kullanılmaktadır (Leek vd., 2016). Bu durum hem B2B, hem de B2C firmalarının hedef kitlelerine ulaşmasında önemli bir rol oynamaktadır. Literatürde B2B firmalarının sosyal medya kullanmaya motive eden faktörleri araştıran çalışmalar incelendiğinde; Michaelidou vd. (2011), B2B firmaların, yeni iş ortaklarını ve fırsatlarını tanımlamak ve müşteri çekmek için kullanıldığını; Kaplan ve Haenlein (2010) ise, mevcut tüketicilere ulaşmak için sosyal medya platformlarını etkin bir şekilde kullandıklarını ve kullanıcılardan geribildirim aldıklarını vurgulamaktadır. Bughin vd. (2009), B2B firmaları için sosyal medya platformların kullanımının sağladığı avantajın bilgiye erişim olduğuna dikkat çekmektedir. Özetle, B2B firmalarının sosyal medya kullanımını arttıran, motive eden faktörlerin paydaşlar ve müşteriler ile bilgi paylaşımının sağlanması (Michaelidou vd., 2011), faaliyet gösterdikleri sektörde aktif bir rol almak (Brennan ve Croft, 2012), marka bilinirliğini arttırmak, marka ve ürünler hakkında bilgi sunmak ve hedef kitlelerine hitap etmek (Järvinen vd., 2012), iş ağlarını geliştirme yoluyla pazar paylarını arttırmak (Quinton ve Wilson, 2016) olduğu tespit edilmiştir.

Literatürdeki çalışmalardan hareketle B2B firmaların sosyal medya kullanımını engelleyen faktörlerin; sosyal medya platformlarının firmalar tarafından benimsenmemesi (Swani ve Brown, 2011), yeterli bilgi ve beceriye sahip işgücü eksikliği (Järvinen vd., 2012) ve firma yönetim politikalarından kaynaklı (Habibi vd., 2015) olduğu görülmektedir. Gıda sektöründe faaliyet gösteren hem B2C, hem de B2B firmaları da hedef kitlelerine ulaşmak, hedef kitleleri ile etkileşime girmek ve aynı zamanda firma hakkında bu hedef kitlelerine yönelik bilgi paylaşımında bulunmak için sosyal medya platformlarını kullanmaktadırlar. Literatürde, gıda sektörü ve sosyal medya konularının bir arada incelendiği birçok çalışma bulunmaktadır. Ancak, gıda sektöründe faaliyet gösteren firmaların sosyal medya kullanımını etkileyen motivasyon ve bariyerler konusuna değinilmemiştir. Mevcut çalışmaların, genellikle sosyal medya platformlarını, B2C gıda firmaları ve nihai tüketiciler çerçevesinde incelemiş olduğu, B2B gıda firmaları için ise oldukça az sayıda (Rutsaert vd.,2013; Singh vd., 2017) çalışmanın yer aldığı gözlemlenmiştir. Bu kapsamda, çalışma Türkiye'de gıda sektöründe faaliyet gösteren B2B firmaları örnekleminde incelenmiştir.

\section{VERI VE YÖNTEM}

Endüstriyel pazarda faaliyet gösteren gıda firmaları; hedef kitlesi açısından üreticiler, tedarikçiler, şefler ve aşçılar başta olmak üzere oldukça geniş bir kitleye sahiptir. Bu bağlamda; çalışmada, Türkiye'de gıda sektöründe faaliyet gösteren B2B gıda firmaları seçilerek, bu sektör özelinde sosyal medya kullanımını etkileyen motivasyon faktörleri ile bariyerleri tespit edilmesi amaçlanmışır. Çalışmada gıda sektöründe faaliyet gösteren dört B2B firmasının yöneticileri ile yarı yapılandııımış görüşme formu hazırlanarak 45 ile 60 dakika arasında derinlemesine görüşmeler gerçekleştirilmiştir. Bütün görüşmeler, ses kayıt cihazı kullanılarak kayıt altına alınmış, firmaların isteği doğrultusunda; firma ve görüşülen kişilerin isimleri sakı tutulmuştur. Araştırma modeli olarak örnek olay çalışmasından yararlanılmış ve araştırmanın geçerliliğini ile güvenilirliğini sağlamak amacı veri çeşitlendirme tekniğinden yararlanılmaktadır (Yıldırım ve Şimşek, 2016: 299). Bu amaçla, çalışmada görüşme bulgularını desteklemek amacıyla görüşülen firmaların sosyal medya hesapları da incelenmiştir. Görüşmeler sonucunda elde edilen veriler detaylı bir şekilde incelenmiş, araştırma bulguları ve değerlendirmeler ile çalışmanın geçerliliği (iç ve dış geçerlilik kapsamında) arttırılmaya çalışılmıştır (Aydın ve Kazançoğlu, 2017). Araştırmada, betimsel analiz yöntemi kullanılmıştır. Çalışma kapsamında bir kodlama anahtarı oluşturulmuştur. Buna göre, "sosyal medya platformlarının incelenmesi", "B2B firmalarda sosyal medya kullanım motivasyonları", "B2B firmalarda sosyal medya kullanım bariyerleri” şeklindedir.

\section{BULGULAR}

Araştırmada yer alan şirketler, gıda sektörünün farklı alt kategorilerinde faaliyet gösteren, farklı örgütsel yapılara sahip -çokuluslu ya da aile şirketi gibi-, çalışan sayısı, üretim kapasitesi, satış hacmi gibi değişkenler açısından birbirinden oldukça farklı ölçekte olan işletmelerdir. Görüşmede örnek olay olarak seçilen iki gıda firması B2B alanda sosyal medya hesaplarına sahipken, seçilen diğer iki gıda firmasının ise henüz sosyal medya hesapları bulunmamaktadır. Görüşme yapılan işletmelerden ilki olan S-Chef, 2010 yılında genç bir girişimci tarafından kurulmuştur. Özel baharat karışımları, çeşniler ve gurme soslar üreten firma, İzmir'de kurulmuş olan işletme, sosyal medya iletişimine ilk olarak 2013 yılında, Facebook'ta, nihai tüketici odağında başlamış olup, B2B için ise şu an bir sosyal medya platformu kullanımı ve iletişim kurgusu bulunmamaktadır. Araştırmaya katılan işletmelerden ikincisi olan F-Frozen, 2000 yılında faaliyete geçmiş, Türkiye'nin en büyük ve en modern fabrikalarından birine sahip olan şirket, dondurulmuş gıda kategorisinde, 800'den fazla çalışanı ile yurtiçi ve yurtdışı pazarlarda 
hem endüstriyel hem de nihai kullanıcılara hizmet vermektedir. İşletme, sosyal medya iletişimine 2012 yılında, ana platform Facebook olmak üzere B2C kanalında başlamıștır. Bugün hala aktif bir şekilde Facebook ve Instagram platformlarını sadece nihai tüketici odaklı iletişimde kullanan firmanın, B2B kanalını hedefleyen bir iletişim kurgusu ise henüz bulunmamaktadır. Araştırmada yer alan üçüncü işletme U-Food, küresel arenada birbirinden değerli birçok markayı bünyesinde barındıran, uluslararası bir örgütün tamamıyla endüstriyel pazarları hedef alarak oluşturduğu bir gıda şirketi konumundadır. İşletme, Türkiye'deki sosyal medya iletişimine B2B hedefli olarak 2014 yllında Facebook'ta başlamış olup, bugün hala aktif olarak Facebook ve Twitter platformlarından B2B odaklı iletişime devam etmektedir. Araştırmada yer alan dördüncü ve son işletme ise 2003 yılından bu yana dondurma pazarında faaliyette olan N-Gıda'dır. N-Gıda, hem B2C, hem de B2B için farklı hesaplar üzerinden aktif bir şekilde sosyal medya iletişimi yapmaktadır. B2B hedefli iletişime ise ilk olarak 2015 yılında, Facebook'ta başlamıştır. Araştırmada, katılımcı firmalardan S-Chef ve F-Frozen, her ne kadar B2C hedefli sosyal medya iletişimi yapsalar da B2B hedefli sosyal medya iletişimi yapmayan firma örnekleminde yer alırken, U-Food ve N-Gıda ise B2B hedefli sosyal medya iletişimi yapan firma örnekleminde yer almaktadırlar. Araştırmada öncelikle görüşme yapılan firmaların sosyal medya sayfaları üzerinden yaptıkları iletişim çalışmaları incelenmiş, sosyal medya iletişimine nasıl ve hangi platform üzerinden başladıkları ortaya konulmuştur. B2B hedefli sosyal medya iletişimi yapan firmaların sosyal medya kullanımındaki temel motivasyon kaynakları, iletişim yapmayan firmaların ise bariyerleri araştııııış ve bu yöndeki bulgular ortaya konularak, karşılaştııı maya çalışılıışır. Araştırmada yer alan firmaların sosyal medya kullanımı ve tercihleri de bu gelişim ile örtüşmektedir. Sosyal medyada B2B hedefli iletişim yapan U-Food (2014 yılında) ve N-Gıda (2015 yılında) ise sosyal medya iletişimi için ilk olarak Facebook'u tercih etmişlerdir. Araştırmaya katılan firmaların sosyal medya platformlarından ilk olarak Facebook tercih etme nedenleri incelendiğinde, Facebook'un "yaygın bir şekilde kullanılması", "hedef kitle ile uyumlu olması", "iyi bir reklam altyapısı ve performans ölçümü sunması" firmaların başlıca tercih sebepleri olarak bulunmuştur. U-Food firması Dijital Pazarlama Yöneticisi tercih sebebini:"Ilk Facebook ile başladık. B2B'de hedef kitlemiz şefler ve aş̧̧ılar, daha çok alaylı oldukları için ağırlıklı olarak Facebook'u kullanıyorlar. Bu nedenle Facebook'u seçtik ve bugün hala Facebook bizim dijital pazarlamadaki ana mecramız konumunda... Facebook ile birlikte Twitter'ı kullanıyoruz, Instagram'ı ise 2018 yılı içerisinde kullanmaya başlayacağız."

Dijital pazarlamada sosyal medya kullanımına ilk adımı Facebook ile atan ve devamında bu iletişimi Instagram ve ya Twitter platformları ile desteklemeye çalışan katılımcıların, B2B hedefli sosyal medya kullanma motivasyonları araştııılı̆ıında, temel motivasyon kaynaklarının "daha geniş kitlelere ulaşma" ve "hedef kitleye etkin bir şekilde erişim ve etkileşim kurma" olduğu görülmektedir. Buna ilişkin olarak katılımcıların ifadeleri şu şekildedir: "Pazarlama açısından düşündügümüzde, müşterilerimize mümkün olduğu kadar her koldan ulaşmaya çalışıyoruz. Hızla dijitalleşen dünyada, tüketicilerimize dokunabileceğimiz en önemli mecralar haliyle dijital mecralar olarak ön plana çıkmakta...Örneğin, bir post ile 1 milyon kişiye anında erişebiliyoruz. Hem tüketicileri yakalamada doğru noktalar olması, hem de hız, etkinlik ve maliyet bizim ana motivasyon kaynaklarımız..." (U-Food). Buradan hareketle, katılımcıları B2B iletişimde sosyal medya kullanıma iten temel motivasyon kaynaklarının öncelikle hedef kitle dâhilinde geniş bir kitleye ulaşma ve kendi markaları özelinde yarattıkları bu onlinesosyal toplulukları ile etkin bir şekilde iletişim kurma ve iletişimde sürekliliği sağlayabilme olduğu anlaşılmaktadır. Bu iki temel motivasyon faktörünün yanı sıra, B2B iletişimde firmaları sosyal medya kullanımına sevk eden bir diğer önemli motivasyon kaynă̆ı "ilave satış geliri yaratma" olarak karşımıza çıkmaktadır. Katıımcı firmalar bu konuyu şu şekilde ifade etmektedirler: "Sosyal medya iletişiminin satışa dönüşüp dönüssmediği tabi ki de bizim için çok önemli. Örneğin, 2018 yılı ilk çeyreğinde Webshop'ı açıyoruz. Webshop, bir e-ticaret sitesi mantığında kurguladığımız ve ürünlerimizi satışa sunduğumuz bir online kanal. Hedef kitlemizi, sosyal medya üzerinden yaptığımız kampanyalar ile Webshop'a yönlendirerek, ürünlerimizin satışını artırmayı hedefliyoruz." (U-Food). "B2B kanalında şu an için ana hedefimiz daha çok görünürlük yakalamak olsa da önümüzdeki dönemde reklamlarımızı görerek sipariş veren kullanııılarımıza, indirim kodları vererek özel indirim uygulamaları yapmayı planlıyoruz." ( $\mathrm{N}$-Gıda). Katılımcı firmaların, her ne kadar sosyal medya platformları üzerinden şu an için direkt bir satış yaratamadıkları görülse de, bu yöndeki beklenti, istek ve çabaların firmaları sosyal medyayı kullanmaya motive eden önemli bir itici güç olduğu net bir şekilde görülmektedir. U-Food'un bu düşünceyi destekler nitelikte bu ifadeyi kullanmıştır. "Biz bu alana çok inanıyoruz. Geleneksel mecralara kıyasla sosyal medya her anlamda hala çok bakir bir alan, ne yaparsak iyi bir mesafe kat edebiliyoruz. Şirketimizin de satış modeli değişiyor, teknolojik gelişmelerle birlikte hızla dijitalleşiyor, bu da bizi daha çok motive ediyor." Sosyal medya üzerinden direkt satış yaratma motivasyonu, firmaların sosyal medya iletişim stratejilerinde -hem altyapı hem de içerik- önemli değişimler yaratmaktadır. B2B firmalarda sosyal medya kullanım motivasyon teması incelediğinde, temel motivasyon kaynaklarının sırasıyla "daha geniş kitlelere ulaşma", "hedef kitleye etkin bir şekilde erişim ve etkileşim kurma", "ilave satış yaratma" ve "marka / kurum bilinirliği yaratma ve artırma” alt temalarında toplandığı görülmektedir. Yapılan görüşmeler sonucunda; “Rakipler karşısında rekabet üstünlüğü yakalama / koruma", "trend ya da moda olması" ve "sosyal medya hesabına sahip olma zorunluluğu hissetme" gibi faktörlerin ise katııımcı firmalar tarafından bir motivasyon kaynağı olarak görülmediği anlaşılmaktadır.

Her ne kadar B2C kanalında sosyal medya kullanımları olsa da, B2B hedefli sosyal medya iletişimi yapmayan katılımcı firmaları, bu kanalda sosyal medya kullanımından alıkoyan faktörler incelediğinde, F-Frozen firması için ilk bariyerin "endüstriyel pazarın sosyal medya iletişimine intiyacı olmaması düşüncesi" ve S-Chef içinse ilk bariyerin "insan kaynağı ve finansal kaynak yetersizliği" olduğu tespit edilmiştir. Buna ilişkin kullanılan ifade : "B2B satış kanalında ağırıkı olarak ticaret bayilik sistemi ve toptancılar üzerinden ilerliyor. Penetrasyon ve pazara erişim için pazarı domine eden büyük satıcılarla ișbirliği kuruyor ve pazara bu şekilde nüfuz ediyoruz. Dolayısıyla, ürün temas nokta sayısı yüksek olmasına rağmen, kanaldaki işbirlikçi sayııının az olması nedeniyle sosyal medya iletişimini şu aşamada B2B kanalında bir ihtiyaç olarak hissetmiyor, net bir ihtiyaç görmüyoruz." (F-Frozen). "B2B kanalında sosyal medya iletişimi yapamamamızın en büyük sebebi kaynak, yetersizliği... Insan kaynağı ve finansal kaynak yetersizliği... En çok da içerik yönetimi oldukça masraflı bir süreç olarak görülüyor. Ancak, şu an için bu alanda firma içerisinde ilave bir istihdam da yaratamıyoruz ve bu nedenle B2B hedefli bir iletişim sürecine giremiyoruz."(S-Chef).B2B hedefli sosyal medya kullanımına etki eden bariyerler söz konusu olduğunda, aynı sektör temsilcisi iki firmadan, iki farklı görüş tespit edilmektedir. F-Frozen, pazarın yapısı, oyuncular ve hedef kitle nedeniyle B2B kanalında sosyal medya iletişimine intiyaç duyulmadığını düşünürken, S-Chef yetkilisi ise kesinlikle, B2B segmentinde de hedef kitlenin iletişim beklentisi olduğuna inanmakta, ancak insan kaynağı ve finans alanındaki kaynak yetersizlikleri nedeniyle sosyal medya iletişimini yapamadığıı ifade etmekte ve eklemektedir. "B2B kanalında zaten herkesin alıcısı belli diye düşünülüyor çoğu zaman. Ama yeni müşteri yaratmada, farkındalık ve tanınırık yaratması açısından sosyal medya kullanımı son derece önemli olduğunu kanısındayım." (S-Chef) 
İnsan kaynağı ve bütçesi olmasına rağmen, tüketici beklentisi ve pazar dinamiği açısından B2B hedefli sosyal medya iletişimine inanmayan F-Frozen Pazarlama Müdürü beklenti ve ihtiyaç bariyeri ile ilgili düşüncelerini aşağıdaki şekilde ifade etmiştir. "Evet, B2B kanalında, ticaretin nokta bazlı değil, daha büyük distribütörlerle yürütüldüğü için böyle bir iletişim ihtiyacı doğmadığını belirtmiştim. Bununla birlikte, nihai tüketicinin, örneğin bir restorana konuk olan müşterinin, tabağındaki patatesin markası ile ilgili bir bağı olmuyor, açıkçası çoğunlukla merak bile etmiyor. Haliyle bu segmentte çok fazla marka konuşulmadığı için örneğin fiyat, ürünün tabaktaki/menüdeki maliyeti, kalite, sevkiyat ve ödeme vadesi gibi daha farklı koşullar ön plana çıkıyor. Bu da tabi ki iletişime yansıyor. Bu arada sadece sosyal medya iletişimi değil, geleneksel iletişimin birçok ögesi de geri planda kalıyor, gereksinim duyulmuyor." B2B bariyerlerin en temelinde "B2B kanalına olan geleneksel bakış açısı" ve "kanala yönelik klasik tutumlar" olduğu kanısına varılmaktadır. Bu geleneksel bakış açısına göre, görüşülen firmaların B2B'de iletişimin yüz yüze ve alanında uzman bir satış temsilcisi ile yapılması gerektiğine inandıkları değerlendirilmiştir.

\section{SONUÇ}

Literatürde, B2B gıda firmaları kapsamında sosyal medya konusu gıda riskleri (Rutsaert vd., 2013); tedarik zinciri iyileştirme (Singh, 2017); kriz yönetimi (Zhu vd., 2017) gibi farklı çerçevelerde incelenmiş olup, B2B gıda firmalarının sosyal medya kullanımını etkileyen motivasyon faktörleri ve bariyerler açısından değerlendiren bir çalışma yapılmamıştır. Bundan dolayı literatüre bir katkı sağladığı düşünülmektedir. Gıda sektöründe faaliyet gösteren B2B firmalar ile yapılan bu araştırma sonucunda; "daha geniş kitlelere ulaşma", "hedef kitleye etkin bir şekilde erişim ve etkileşim kurma", "satış geliri yaratma" ve "marka / kurum bilinirliği yaratma ve artırma"nın, bu firmaların sosyal medya platformlarını kullanmada temel motivasyon faktörleri olduğu belirlenmiştir. B2B firmalarının sosyal medya araçlarının kullanımına yönelik yapılan çalışmalarda (Michaelidou vd., 2011, Brennan ve Croft, 2012, Järvinen vd., 2012, Quinton ve Wilson, 2016) da bu çalışma sonucunda ortaya çıkan motivasyon faktörleri ile paralel olduğu görülmektedir. B2B pazarda faaliyet gösteren firmaları sosyal medya kullanımını engelleyen bariyerler; "endüstriyel pazarın sosyal medya iletişimine ihtiyacı olmadığı düşüncesi” ile "insan kaynağı ve finansal kaynak yetersizliği" olarak tespit edilmiştir. Bu bariyerlerin temelinde ise; B2B kanalına olan geleneksel bakış açısı ve kanala yönelik klasik tutumların etkisi olduğu sonucuna varılmıştır. Elde edilen bulguların, ilgili literatürde daha önceki çalışmalarda (Järvinen vd., 2012, Habibi vd., 2015) birebir örtüştüğü görülmektedir. Çalışma, nitel bir araştırma olmasından dolayı elde edilen bulgular ve sonuçlar tüm sektörler için genellememektedir. Bu çalışmanın diğer sektörler için yapılacak görüşmelerle karşılaştırmalı çalışmalara yol gösterici bir nitelik taşıdığı düşünülmektedir. Sonuç olarak gıda sektöründe faaliyet gösteren B2B firmalarının önündeki bariyerler ortadan kaldırıldığında, bu firmaların mevcut pazarlarında daha aktif bir rol alabileceği ve mevcut müşteri portföylerinin dışındaki potansiyel alıcılar tarafından da dikkat çekmesi beklenmektedir. Gelecekte, elde edilen bulgular doğrultusunda, belirli sektördeki B2B firmalarına yapılacak anket çalışması ile desteklenerek, daha geniş bir örneklem için daha detaylı bir değerlendirme yapılabileceği düşünülmektedir.

\section{KAYNAKLAR}

Aydin, H., Kazançoğlu, ì. (2017). Çoklu kanal stratejisinden bütüncül kanal stratejisine geçişin tüketiciler tarafindan kabulü. Mustafa Kemal Üniversitesi Sosyal Bilimler Enstitüsü Dergisi, Vol. 14, No. 39, pp. 57-77.

Brennan, R., Croft, R. (2012). The use of social media in B2B marketing and branding: an exploratory study. Journal of Customer Behaviour, Vol. 11, pp. 101-115.

Bughin, J., Manyika, J., Miller, A. (2009). How companies are benefiting from web 2.0. The McKinsey Quarterly, ABD.

Filo, K., Lock, D., Karg, A. (2015). Sport and social media research: a review. Sport Management Review, 18 (2): $166-181$.

Habibi, F., Hamilton, C. A., Valos, M. J., Callaghan, M. (2015). E-marketing orientation and social media implementation in B2B marketing. European Business Review, Vol. 27 No. 6,pp. 638-655.

Järvinen, J., Tollinen, A., Karjaluoto, H., Jayawardhena, C. (2012). Digital and social media marketing usage in B2B industrial section. Marketing Management Journal, Vol. 22, No. 2, pp. 102-117.

Kaplan, A. M., Haenlein, M. (2010). Users of the world, unite! The challenges and opportunities of social media. Business Horizons, Vol. 53, pp. 59-68.

Lacka, E., Chong, A. (2016). Usability perspective on social media sites' adoption in the B2B context. Industrial Marketing Management, Vol. 54, pp. 80-91.

Leek, S., Canning, L., Houghton, D. (2016). Revisiting the task media fit model in the era of web 2.0: Twitter use and interaction in the healthcare sector. Industrial Marketing Management, Vol. 54, pp. 25-32.

Michaelidou, N., Siamagka, N. T., Christodoulides, G. (2011). Usage, barriers and measurement of social media marketing: an exploratory, investigation of small and medium B2B brands. Industrial Marketing Management, Vol. 40, pp.1153-1159.

Quinton, S., Wilson, D. (2016). Tensions and ties in social media networks: towards a model of understanding business relationship development and business performance enhancement through the use of LinkedIn. Industrial Marketing Management, Vol. 54, pp. 15-24.

Rutsaert, P., Regan, A., Pieniak, Z., McConnon, A., Moss, A., Wall, P., Verbeke, W., (2013). The use of social media in food risk and benefit communication. Trends in Food Science \& Technology, Vol. 30 No.1, pp. 84-91.

Siamagka, N. T., Christodoulides, G., Michaelidou, N., Valvi, A. (2015). Determinants of social media adoption by B2B organizations. Industrial Marketing Management, Vol. 51, pp. 89-99. 
Singh, A., Shukla, N., Mishra, N. (2017). Social media data analytics to improve supply chain management in food industries Transportation Research Part E. Vol. 114, pp. 398-415, http://dx.doi.org/10.1016/j.tre.2017.05.008 1366-5545/.

Swani, K., Brown, B. P. (2011). The effectiveness of social media messages in organizational buying contexts. American Marketing Association, Vol. 22, pp. 519.

Yildirim, A., Şimşek, H. (2016). Sosyal bilimlerde nitel araştırma yöntemleri. (10. Baskı). Ankara: Seçkin Yayıncılık.

Zhu, L., Anagondahalli, D., Zhang, A. (2017). Social media and culture in crisis communication: McDonald's and KFC crises management in China. Public Relations Review, Vol.43, No. 3, pp. 487-492. 